\title{
Um olhar fenomenológico sobre a questão da saúde e da doença: a cura do ponto de vista da Gestalt- terapia
}

\section{Gestalt therapy: a brief notion on Phenomenological Psychopathology}

\section{Loeci Maria Pagano Galli}

Doutora em Comunicação Social Pela Pontifícia Universidade Católica Do Rio Grande do Sul/PUCRS - Porto Alegre, RS, Brasil

\begin{abstract}
Resumo
O comportamento de uma pessoa não pode ser compreendido como um fenômeno isolado do mundo exterior. É preciso entender um sintoma como um estilo de ser-no-mundo. Para Heidegger o homem não "é" primeiramente, ele é homem na exata medida de seu ser-em-relação. Qualquer diagnóstico pressupõe uma teoria a priori sobre a pessoa. Diagnosticar para um gestalt-terapeuta significa conhecer e respeitar o ser humano ao longo de sua existência. Um sintoma exige atenção, pois é um transmissor de informações, todo evento mental tem repercussões no organismo.

O conceito de "cura" para Gestalt-terapia só pode ser compreendido a partir de uma concepção fenomenológica-existencial do ser humano.

Palavras-chave: Gestalt-terapia, Psicopatologia, Fenomenologia.
\end{abstract}

\begin{abstract}
A person's behavior cannot be perceived as an isolated phenomenon in the outside world. It is necessary to understand a symptom as a style of beingin-the-world. Heidegger claims that before being a man exists to the extent of his being-in-relation-to-his-environment.

Any diagnosis firstly implies theory. Diagnosing for a gestalt therapist means knowing and respecting human beings throughout their existence. A symptom demands attention, for it conveys information - every mental event has repercussions in the body.

The concept of "cure" for Gestalt Therapy can only be understood from a phenomenological and existential conception of human beings.

Keywords: Gestalt-therapy, Psychopathology, Phenomenology.
\end{abstract}


A perspectiva de uma psicopatologia fenomenológica toma suas origens da filosofia alemã e, mais particularmente, da obra de Husserl (1859-1938) e de Heidegger (1889-1976). A contribuição da fenomenologia conduziu a uma pluralidade de pontos de vista em psicopatologia. Dois métodos são mais conhecidos, o primeiro - que se pode qualificar de descritivo dos fenômenos de Karl Jaspers (1883-1969), em cuja concepção a psicopatologia ocupa-se, sobretudo como os "doentes" vivem - visa desvelar significações. O segundo método é o de Ludwig Binswanger (1881-1966) e seu trabalho conduz à Daseinsanalyse (análise existencial, análise da presença humana), atitude partindo da compreensão do homem em todas as suas formas e todos os seus mundos. De acordo com Binswanger, é preciso compreender o mundo do "doente" e situar os momentos que contribuíram para desenvolver a estrutura de sua personalidade.

Os planos qualitativos de pesquisa iniciam-se com observações específicas, com o exame minucioso de casos individuais. Tentar compreender os fenômenos tais como naturalmente vão surgindo constitui a própria justificativa da utilização de planos qualitativos, de empregar uma análise indutiva, e do desenrolar na forma de uma entrevista naturalista.

A reflexão de Heidegger em Ser e Tempo (Sei und Zeit, 1927) sobre o ser humano, segundo Binswagner, tornou-se indispensável para a psiquiatria enquanto ciência. Sua ontologia fundamental não apenas converteu-se num marco do pensamento filosófico do século $X X$, como causou grande repercussão nas ciências humanas.

A noção do ser-no-mundo difundiu-se amplamente pelas ciências humanas desde que foi formulada por Martin Heidegger no tratado Ser e Tempo. Ele busca em sua obra o sentido do ser. A investigação fenomenológica de Heidegger é de caráter ontológico ${ }^{1}$, isto é; busca as determinações essenciais do ser dos entes ${ }^{2}$. Dessa maneira pretende sempre se situar aquém do plano empírico ou ôntico ${ }^{3}$ (dos entes) e constituir-se na condição de possibilidade do mesmo.

O ser no mundo pode ser desmembrado em três partes: o "ser", o "mundo" e o "em". O mundo em que o ser é, o quem é no mundo, e o modo de ser-em-si-mesmo. A mundaneidade (materialidade) só se deixa caracterizar mediante a compreensão do ser para quem existe um mundo, o ser que é-no-mundo, por sua vez, só se revela a partir de sua "morada" (o mundo), e a relação de ser-em pressupõe a compreensão dos termos que se relacionam no modo do "em". O homem não "é" primeiramente para depois criar relações com um mundo, ele é homem na exata medida de seu ser-em, isto é, na exata medida em que possui um mundo ou abre o sentido de um mundo.

Não há sentimento, comportamento ou qualquer outro modo de ser de uma pessoa que exista isoladamente como um fenômeno "em si". 
Se olharmos de perto, veremos que a angustia de uma pessoa, que nos parece "vir de dentro", está também "fora", que em última instância não existe nem "dentro" e nem "fora" e que em seu ser, alguém só se angústia porque o mundo o arrasta em sua angústia, isso reflete uma inseparabilidade.

A perspectiva ontológica compreende um sintoma ou síndrome não como uma coisa individual, mas como um estilo de ser no mundo, uma postura total, e que como tal pode ser encontrado em vários domínios da atividade humana.

O sintoma enquanto estilo de ser é um modo do ser-aí impregnado de uma determinada experiência. A abordagem existencial, portanto opera a partir da compreensão do mundo como o indivíduo se instalou na estrutura do ser no mundo. Um sintoma pode ser compreendido como um estilo de ser no mundo, no modo que ele se dá existencialmente. De acordo com Merleau-Ponty (1908-1961), o campo fenomenal da experiência vivida, da inserção no mundo, é aquele que dá sentido à existência de certos fatos objetivos isolados (PONTY, 1996).

Sabemos que o organismo é adaptável às condições do meio exterior, os poros fecham-se com o frio, as pupilas dos olhos contraem-se com o brilho da luz. Assim também nos adaptamos psicologicamente. Este processo constitui a interpretação e o ajuste personalizado à realidade de um ser humano único. Toda a pessoa nasce com um valor próprio e incondicional. De acordo com Heidegger (1997), a essência do Dasein ${ }^{4}$ encontra-se em sua existência; não há essência do ser", já que ser-uma-essência é em si mesmo um modo de ser. A questão é sobre o que "faz" um ente ser o que ele é, portanto sobre o que perfaz seu ser-o-que, sobre a entidade dos entes.

Essência é aqui apenas uma outra palavra para ser (no sentido de entidade). Significa o acontecimento à medida que acontece. Ser não é: ser "essencializa". A essência do Dasein encontra-se em sua existência. O Dasein é responsável pelo seu ser-com. O Dasein "dá um passo á frente" para dentro do mundo e faz algo de si mesmo; ele é "ecstático", excêntrico. Existenz não envolve nenhum contraste com "essência" ao contrario de Sartre de que a existência precede a essência. Heidegger frequentemente escreve ex-sistenz ou Ek-sistenz para enfatizar o "passo para fora". Faz-se presente por si mesmo.

O conceito "existencial" (o de Heidegger) de existência significa o ser si mesmo do homem, à medida que está relacionado não com o si mesmo individual, mas com o ser e a relação com o ser.

A percepção que cada um tem sobre si estará sempre afetando suas outras atitudes, influenciando sua forma de ver e contatar a realidade. Exemplo: se me imagino fracassado, ajo como tal, independente das situações novas vivenciadas. Assim, as expectativas de fracasso dão luz aos próprios fracassos. 
Se uma flor for atingida por uma forte geada fora da estação, ela não se abrirá; a pessoa da mesma forma, quando não recebe amor, afeto, afago, precisa suportar sua ausência, assim seu afeto se torna preso em si mesmo. Quando a dinâmica da personalidade apresenta danos, chama-se comumente de neurose ou psicose; os gestaltterapeutas chamam de ajuste criativo. O terapeuta precisa ver 0 valor criativo em uma resistência; embora ela seja evitação de um comportamento, na verdade ela é contato intra-psíquico, pois se protege de um possível sofrimento. Estar encoberto é uma realidade existencial, não um estado patológico. O reconhecer este existencial de forma compartilhada é que permite a "cura". Podemos entender conflitos interiores como conflitos entre a existência do organismo e o social.

Na Gestalt-terapia, a fenomenologia é empregada como método, quer dizer que é preciso observar a realidade com atenção, descrevê-la no sentido lato do termo. A totalidade ocorre no "aqui e agora", portanto é mister estar atento à temporalidade e à espacialidade na qual a pessoa se movimenta e se revela na vida. É importante observar a pessoa no seu modo de agir verbal e não-verbal:

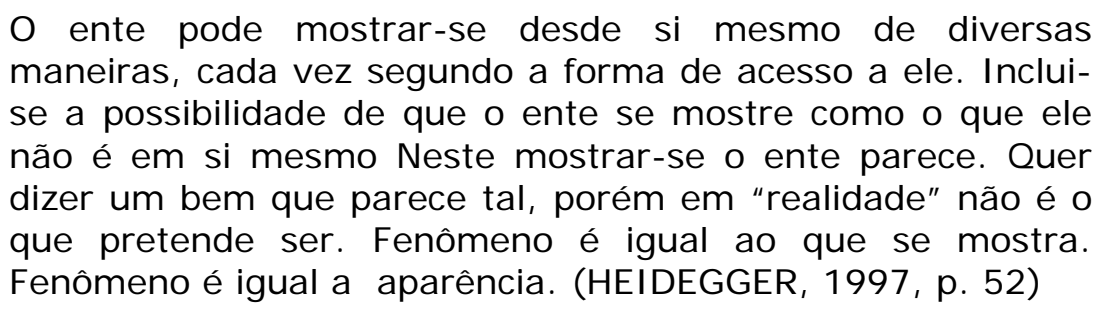

Em qualquer diagnóstico há sempre uma visão do mundo antes do mundo, uma teoria antes de uma pessoa, um saber antes de um acontecer. Diagnosticar é aprisionar o ser do outro. Perls (1997) fez a ruptura com a frieza e o distanciamento para dar lugar ao encontro humano e ao conviver.

Perls definia a saúde e a maturidade psicológica como sendo a capacidade de emergir do apoio e da regulação ambientais para um auto-apoio e uma auto-regulação, onde o elemento fundamental no auto-apoio e na auto-regulação é o equilíbrio. Uma das premissas básicas da Gestalt-terapia considera que todo o indivíduo possui potencialidades naturais que possibilitam buscar o equilíbrio do seu organismo. Perls considera o ritmo de contato/fuga com o meio ambiente como o componente principal do equilíbrio organísmico.

Indivíduos auto-apoiados e auto-regulados caracterizam-se pelo livre fluir e pelo livre delineamento mais claro da formação figura-fundo nas expressões de suas necessidades de contato e retraimento.

Diagnosticar um ser humano no contexto da psicoterapia implica acompanhá-lo, conhecê-lo ao longo de sua existência, através das relações que ele estabelece com e em seu mundo, através da sua 
relação comigo, com as relações que ele mantém com seus eus, tus e issos, com os quais interage nos tempos e espaços que segue percorrendo.

Terapeutas acompanham o paciente no indispensável encontro com a inevitável dor da vida, com as possibilidades trágicas de sua existência, com suas perdas, com a impermanência, com a própria morte. Fugir da dor da vida, apartar-se da própria história, é perder o sentido da existência humana, é deixar de ser...

Um gestalt-terapeuta não escamoteia a dor, mas acredita na liberdade de atitude frente ao próprio destino, e, portanto, nas dimensões prazerosas da vida. É este ser humano em movimento, senhor e intérprete de sua história, que me permite conhecê-lo. Os conceitos e teorias só servem para acompanhar-lhe o fluxo. Não se imagina trabalhar sem lógica, sem sistemas de pensamento, sem "verdades", mas rejeita-se qualquer pensamento que se creditem absolutamente verdadeiros. O trabalho incentiva o conhecer quando se tem por premissa que o conhecimento jamais se completará de fato. Há um universo inesgotável das possibilidades do viver de um único ser humano.

Segundo Karen Horney (1885-1952), o conceito do que é normal varia não só com a cultura, mas também dentro da mesma cultura, e como nossa cultura gera uma grande dose de ansiedade nos indivíduos, as defesas desenvolvidas ficam potencializadas (HORNEY, 1964).

Em qualquer esforço para compreender uma personalidade é indispensável perceber a natureza e a complexidade do seu desenvolvimento não subestimando os labirintos da natureza do homem atual, que muitas vezes é conduzido à autodespistamentos, ilusões, fabricação artificial de desejos. A sociedade hiper-industrial pode privar os seres humanos de sua individualidade, de sua singularidade.

Ainda para Karen Horney (1964), o conflito oriundo de atitudes incompatíveis constitui o âmago das neuroses que exprimem uma perturbação nas relações humanas. Não é por mero acidente que um conflito inicia-se em nossas relações com os outros e afeta o desenvolvimento da personalidade. As relações humanas são decisivas para moldar as qualidades que desenvolvemos, as metas que fixamos, os valores que acreditamos, tudo fica nas relações inextricavelmente entrelaçado. Por ser uma vida orientada em relação aos outros, o resultado do que aparece na superfície representa tentativas para encontrar uma solução para o momento e não para o conflito propriamente dito.

Temos que confiar na pessoa como produtora de significados. As experiências do passado determinam a maior ou menor confiança nela mesma, ela é também seu passado, ele integra seu todo. 
Terapia é fortalecimento da pessoa como ser-no-mundo, de fazer a sua leitura e acreditar nela. O papel do terapeuta é muito ativo. Para o indivíduo confiar em si, ele tem que se sentir acompanhado. É preciso respeitar as características culturais do indivíduo e utilizá-las para ajudá-lo durante a terapia. A etnopsiquiatria leva em conta a origem cultural do paciente e os dispositivos terapêuticos existentes em cada cultura. Devemos compreender um sintoma como um estilo de ser no mundo, no modo que ele se dá existencialmente.

De acordo com Maffesoli (2001), hoje há uma formidável liberdade, mas estéril para o pensamento, não sabemos o que há para pensar. As pessoas não se interrogam mais sobre sua própria existência. Como faltam referências, o indivíduo se vê exposto, frágil, deprimido, precisando sempre de confirmação externa, assim o eu que aparentemente está voltado para si como o culto ao corpo, a busca de prazer insaciável, a competição pelo trabalho, está cada vez mais perdido de si mesmo, gerando estados depressivos diversos.

Nas patologias da pós-modernidade vemos conseqüências físicas e emocionais, como insônia, esgotamento físico e mental, transtornos alimentares e de humor, auto-estima rebaixada e dificuldades de estar e cuidar de si mesmo.

O stress é desencadeado pela acentuada competição no ambiente de trabalho; as dificuldades percebidas em suas inter-relações afetivas e sociais geram um tipo de pressão interna experimentada sob a forma de sensações difusas de medo e sentimento agudo de vazio e isolamento interno. Queixas desta natureza compõem um quadro nosológico específico de nossa contemporaneidade exigindo muito do individuo.

A violência social e econômica é muito mais grave que a guerra. A economia liberal imperante no mundo transforma os sujeitos em objetos. Esta violência é pior que a guerra porque é generalizada. Pessoas são levadas á depressão, jogadas na rua e no desemprego, com a perda da sua subjetividade e raízes. A Gestalt-terapia busca humanizar, retomar a chance de refletir sobre a própria vida e permitir contestar a ordem estabelecida que transforma os homens em mercadorias. Uma pessoa integrada tem noção de sua harmonia, de seu equilíbrio interior, age no mundo com base na sensação presente, respeita suas possibilidades existenciais.

Se nos dedicarmos somente ao tratamento dos sintomas, eles podem até desaparecer, mas é certo que serão substituídos por outros. As pessoas querem curar-se, atenuar seus sintomas rapidamente, mas a aventura do auto-conhecimento pode ser lenta. Sem espaço para agir e sem condições de modificar situações que as incomodam, a reação é a contração física. O caminho mais fácil para preencher esse vazio interior que toma conta das pessoas, o vazio que causa ansiedade, seria, então, a pílula mágica que auxilia a amenizar seus relacionamentos interpessoais. 
Ter um antidepressivo guardado na carteira já é sinal de status. Um bom ansiolítico e um hipnótico eficaz são objetos de consumo que não devem ser esquecidos na despesa do mês.

As pessoas não toleram a depressão em si e nos outros, na nossa sociedade os indivíduos são conduzidos a mover-se, fazer coisas, a tomar decisões, a agir, e quem fica sozinho num canto é visto com restrições. É curioso notar que a forma de considerarmos a doença "bipolar" em que existe um pólo maníaco e outro depressivo, obedece a uma determinação social. O maníaco é mais aceito pelas sociedades competitivas do que o depressivo. O sujeito que diz que vai construir um prédio de 500 andares ou que dentro de um ano terá um milhão, é tido como empreendedor, mas se alguém fica quieto, pensativo, não faltará quem diga que ele não está bem que deve tomar alguma providência. Daí surge o sucesso das drogas. Os dois são desequilíbrios do encontro consigo mesmo. Se observarmos as polaridades, impotência $X$ onipotência, o equilíbrio está no meio que é a potência.

Nossa cultura está repleta de pessoas viciadas em algo, drogas, álcool, comida, cigarro, trabalho, televisão, dinheiro, poder, relacionamentos, religião, maneiras de nos preenchermos com coisas externas a nós. O que aconteceu com a sociedade que provocou este vazio? Por que tantos casamentos infelizes, tanta ansiedade, tanta depressão, tantas enfermidades, por que tantas pessoas infelizes, sofridas, capazes de se depreciar, sentindo-se solitárias, vazias ?.

Sentimo-nos sós quando perdemos a conexão conosco, ficamos isolados, individualistas, não conseguimos nos vincular aos outros, enquanto não fizermos o nosso próprio vínculo. Não existe uma reação orgânica sem uma repercussão mental. Todo evento mental tem repercussão no organismo. Uma enfermidade explica algo sobre o momento de vida. Nossa matriz psicológica e nosso corpo são complexos.

Formular um remédio que propicie um estado de felicidade imune aos psíquismos, imperturbável diante das vicissitudes da vida, não é do humano, mas parece estar sendo o caminho mais fácil para preencher um vazio que causa ansiedade. A busca da pílula mágica substitui a falta de relações interpessoais mais íntimas, elas estão tênues.

Hipócrates, considerado o pai da medicina, séculos antes de Cristo, compreende que o corpo não é só um somatório de órgãos, mas sim uma unidade viva, regulado e harmonizado por cada indivíduo. Assim, podemos entender que tudo o que a consciência rejeita como material culposo, vergonhoso ou sofrido pode se materializar em enfermidade. Para qualquer pessoa manter o seu emocional em equilíbrio é fundamental que ela sinta-se amada e que tenha um papel no mundo que possa dar sentido à sua existência. 
Segundo Heidegger (1997) o homem recusa seu próprio ser, cujo sentido se anuncia, mas se acha oculto. O homem vive como qualquer um, bebe, come, dorme, trabalha, sua despersonalização anula qualquer originalidade, ele vive na inautenticidade. O homem autêntico é aquele que se projeta no tempo sempre em direção ao futuro. Esta passagem não se faz sem dificuldade, mas com ela o homem sai da facticidade e entra na transcendência, sair da inautenticidade é buscar a estrutura original da pessoa, pesquisar os bloqueios adquiridos no decorrer da existência, mobilizá-los e modificá-los para que a pessoa adquira uma conduta nova. O Dasein autêntico ou decidido adianta-se muito mais no futuro do que o Dasein cotidiano e, correspondentemente, recua muito mais no passado, antes de vir a pousar no presente e fazer o que ele tem de fazer agora.

O objetivo terapêutico é observar se o homem pode ou se está disposto a despertar de seu sonho e tomar parte na vida universal. Perls manteve a idéia de que a mudança não pode ser forçada e que o crescimento psicológico é um processo natural e espontâneo. Ele também desenvolveu a noção de um continuum de consciência como um meio de encorajar esta autoconscientização. Manter um continuum de consciência parece decepcionantemente simples apenas estar consciente do que estamos experienciando a cada instante, no entanto a maioria das pessoas interrompe o continuum quase imediatamente, interrupção que é causada pela conscientização de algo desagradável.

Esta fuga de uma conscientização contínua, esta auto-interrupção, impede a pessoa de encarar e assimilar uma conscientização desagradável, a situação (gestalt) fica inacabada. Evitar a consciência é enrijecer o livre fluir natural do movimento figura-fundo.

Para Koestler (1978), há uma tendência entre os holistas de usar a palavra "todo" ou gestalt como algo completo em si mesmo, que não requer ulterior explicação. Mas todos e partes, neste sentido absoluto, não existem em lugar nenhum, nem no domínio dos organismos vivos, nem nas organizações sociais. A neurose é contextual e funcional. Contextual porque é uma resposta do ser no mundo, desenvolvida num determinado contexto.

Não adianta ficar procurando a origem do sofrimento psíquico apenas no inconsciente, como fazem as correntes que buscam sua origem no orgânico. Há outros fatores no mundo real, como viver numa cidade violenta ou o medo de perder o emprego, que podem, por exemplo, levar alguém à depressão.

Ter a idéia de que há um universo só seu, bem separado da vida social não contribui para uma conceito natural sobre o indivíduo, ele é produto de uma época, e, como tal, muda de tempo em tempo e pode variar de cultura para cultura. 
Além das relações familiares, outras fontes são geradoras de sofrimento, como a pressão no trabalho ou mesmo a exigência de se enquadrar num padrão de beleza. No lugar de classificar o paciente dentro de um quadro de doenças psíquicas, é preciso analisar as forças que estão atuando para produzir esse sofrimento.

Os sintomas podem ser considerados a forma física ou psíquica de expressão dos conflitos e têm a capacidade de mostrar às pessoas em que consistem seus problemas. Tudo o que acontece no corpo de um ser vivo é a expressão do padrão correspondente de informação, ou seja, é a condensação da imagem correspondente.

O sintoma exige nossa atenção, quer queiramos ou não. A interrupção das funções é sentida como se viesse de fora, como se fosse uma perturbação, na maioria das vezes, a intenção do sintoma é fazer desaparecer o elemento irritante, a perturbação.

A medicina acadêmica equipara o sintoma à doença e está encantada com os sintomas, mas não parece querer compreender o ser humano por inteiro. A doença é um estado do ser humano, indicativo de que, a sua consciência não está mais em ordem, ou seja, sua consciência registrou que não há harmonia, essa perda de equilíbrio interior se manifesta no corpo ou na mente com um sintoma, sendo assim o sintoma é um sinal e um transmissor de informações, pois com seu aparecimento, ele interrompe o fluxo da nossa vida e nos obriga a prestar-Ihe atenção. O sintoma nos informa que está faltando alguma coisa. Antigamente perguntava-se o que está lhe faltando? Hoje pergunta-se logo no início "o que o Sr. sente?". A consciência sempre capta a falha de alguma coisa.

Assim, quando entendemos esta diferença, o sintoma passa a ser visto como um companheiro capaz de descobrir o que lhe falta. Sintomas querem dizer coisas muito mais importantes que nossos semelhantes, pois são parceiros muito mais íntimos. Ouvir ou entender os sintomas não fará com que eles desapareçam. Na medida em que nos conscientizarmos do que nos falta, do que ainda temos de integrar em nós mesmos, teremos a oportunidade de transformar os sintomas em algo de que não necessitamos mais. Esta é a diferença entre lutar contra a doença e transmutá-la.

A cura acontece através da incorporação daquilo que está faltando e, portanto, ela não é possível sem uma expansão da consciência. Entender o ser humano pressupõe estar aberto a fatos novos, mesmo que não se encaixem com os já catalogados, isto nos torna capazes de criar.

Na psicose, a própria estrutura da percepção fina da lógica de orientação tempo/espaço da pessoa está perturbada. Uma personalidade pode apresentar dificuldades com a awareness das coisas que são dolorosas e ameaçadoras, retirando-lhe a capacidade de auto-observação contínua exigida. 
Não existe uma reação orgânica sem uma repercussão mental. Todo o evento mental tem repercussão no organismo. A enfermidade explica algo sobre o momento de vida. As causas que o paciente atribui ao adoecimento são verdades psicológicas que revelam como a pessoa está vivendo e quais as questões existenciais que enfrenta. O paciente não inventa histórias; quando ouvido, ele fala de suas dores. A dor do corpo é uma dentre elas. Nossa matriz psicológica e nosso corpo são complexos. Higiene psicológica é cuidar dos nossos sonhos, sentimentos e relacionamentos. Alguém na escola ensinou você a expressar e lidar com seus sentimentos?

Toda a doença tem um significado único para o seu portador e isso deve ser entendido dentro do contexto atual de vida. Temos um conhecimento psicológico do nosso corpo mais do que nos damos conta. Uma das formas de entrar em contato com esse conhecimento é a imaginação. Por ex: diante da pressão interna para ser eficiente, uma cliente, em sua imaginação, lembra do pai. O temor da explosão do pai se incorporou no seu sistema cardiovascular. Esse medo inconsciente era maior do que o pavor de morrer sem cumprir tarefas.

De acordo com Goswami (2000), nossos corpos mental, vital e físico não são apenas interdependentes por meio de vários sistemas (físicos) corporais, mas, em última análise, também estão interligados por meio da consciência. Esta concepção da vida da célula, como uma identificação manifesta da consciência nos proporciona um modelo totalmente novo da conexão mente-corpo diferente do atual modelo dualista da medicina.

O novo modelo leva a uma nova abordagem da doença e da cura, baseada na idéia da criatividade do corpo no nível mental e no nível vital. O pensamento emotivo, por oposição ao pensamento racional, está sendo reconhecido como uma causa do efeito "mente que mata / mente que cura" nossas emoções negativas como o medo, a luxuria e a raiva estão ligadas às representações condicionadas dos movimentos do corpo vital. A nova abordagem faz sentido, se acrescentarmos o conceito de corpo vital quântico, (o corpo vital contém os originais/os campos morfogenéticos), do qual os órgãos do corpo físico são as representações.

A doença é uma química defeituosa nas representações físicas do corpo vital. A doença significa que uma representação em software de uma determinada função vital deu errada, e precisa de um caminho novo e criativo. A cura mente-corpo ocorre quando a consciência criativamente provoca o colapso de novas possibilidades na mente quântica, o que induz o cérebro - e, pela conexão cérebrocorpo, o corpo vital-fisico - a criar uma nova representação, um novo caminho, para a função vital afetada.

O nosso organismo é altamente simbólico e projetamos sobre ele conteúdos inconscientes e cheios de significados. Uma das 
proposições básicas da Gestalt-terapia é que todo organismo possui a capacidade de realizar um equilíbrio ótimo consigo e com seu meio. As condições para realizar este equilíbrio envolvem uma conscientização desobstruída da hierarquia de necessidades.

Perls considera o ritmo de contato/fuga com o meio ambiente como o componente principal do equilíbrio organísmico. Indivíduos autoapoiados e auto-regulados caracterizam-se pelo livre fluir e pelo delineamento claro da formação figura/fundo nas expressões de suas necessidades de contato e retraimento. Tais indivíduos reconhecem sua própria capacidade de escolher os meios de satisfazer necessidades à medida que estas emergem. Têm consciência das fronteiras entre eles mesmos e os outros e estão particularmente conscientes da distinção entre suas fantasias sobre os outros (ou o ambiente) e o que experienciam através do contato direto.

Ao acentuar a natureza do auto-apoio e da auto-regulação no bem estar psicológico, Perls (1997) não quer dizer que o individuo pode existir, de algum modo, separado do seu meio ambiente. Na verdade, o equilíbrio organísmico supõe uma constante interação com o meio. O ponto crucial para Perls é que podemos escolher a maneira "como" nos relacionarmos com o meio; somos auto-apoiados e autoregulados quanto ao fato de que reconhecemos nossa própria capacidade de determinar como nos apoiamos e regulamos dentro de um campo ${ }^{5}$ que inclui mais do que nós mesmos.

O conceito de cura que a Gestalt-terapia se propõe só pode ser compreendido a partir da concepção fenomenológica-existencial do ser humano. Esta concepção se opõe radicalmente ao controle, à manipulação ou à correção que representam saídas autoritárias e simplistas. A concepção que temos do ser humano e do mundo vai de encontro às concepções institucionalizadas e com o tipo de crenças que nos impuseram e estão impregnadas.

Somos profissionalmente tomados pela compulsão do "orientar", "do resolver", "do salvar", "do curar", "do educar" e com isso tiramos a oportunidade da pessoa encontrar seu próprio caminho, além de vislumbrar soluções possíveis. Para nós, cura não é solucionar problemas, mas entrar em contato consciente com o sábio, que cada um tem dentro de si e, a partir daí, realizar o que esse sábio decidir.

Esta mudança, no entanto, só acontece se você comprometer-se a praticar todos os dias. Você se apresentaria para um recital de piano sem ter praticado diariamente durante meses e atingido um ponto em que acreditasse estar apto a tocar? Mesmo na situação de depressão é preciso obter alguma certeza de ser capaz de dar conta de uma situação crítica. Escutar-se verdadeiramente requer muita prática.

Cura é acreditar em nós mesmos, no outro e no mundo. 


\section{Referências Bibliográficas}

BERG, J. H. V. O Paciente Psiquiátrico. esboço de psicopatologia fenomenológica. São Paulo: Mestre J ou, 1981.

DAHLKE, R. A doença como caminho. São Paulo: Cultrix, 2001. GOSWAMI, A. A janela visionária. São Paulo: Cultrix, 2000.

O médico quântico:orientações de um Físico para a saúde e a cura. São Paulo: Cultrix, 2006.

HEIDEGGER, M. Ser y Tiempo. Tradução de Jorge Eduardo Rivera. Santiago do Chile: Editorial Universitária, 1997.

HORNEY, K. A personalidade neurótica do nosso tempo.Rio de J aneiro: Ed. Civilização Brasileira, 1964.

Nossos conflitos interiores. Rio de Janeiro: Civilização Brasileira, 1964.

INWOOD, M. Dicionário Heidegger. Rio de Janeiro: Jorge Zahar Editor, 2002.

IONESCU, S. Quatorze Abordagens de Psiocopatologia. Porto Alegre: Artes Médicas, 1997.

KOESTLER, A. Jano. São Paulo: Melhoramentos, 1978.

MAFFESOLI, M.O eterno instante.O retorno do trágico nas sociedades pós-modernas. Lisboa: Instituto Piaget, 2001.

PERLS, F. A Abordagem Gestáltica e Testemunha Ocular da Terapia. Rio de Janeiro; Zahar, 1981.

PERLS, F; HEFFERLINE, R; GOODMAN, P. Gestalt-Terapia.São Paulo: Summus, 1997.

PONTY, M. M. Fenomenologia da percepção.São Paulo: Martins Fontes, 1996

RIBEIRO, W. Existência - Essência: Desafios Teóricos e Práticos das Psicoterapias Relacionais. São Paulo: Summus, 1998.

WAELHENS, A. A Psicose - ensaio de interpretação analítica e existencial. Rio de Janeiro: Ed. Jorge Zahar, 1990.

\section{Endereço para correspondência}

Loeci Maria Pagano Galli

GESTAL - CENTRO, Av. Luiz Manoel Gonzaga, 351/301, CEP 90470-280, Porto Alegre-RS, Brasil

Endereço eletrônico: igestalt@igestalt.psc.br

Recebido em: 28/05/2008

Aceito para publicação em: 08/04/2009

Editor responsável: Laura Cristina de Toledo Quadros

\section{Notas}

${ }^{1}$ Ontológico designa o pensar curioso, espantado, assustado sobre o fato de que eu existo e de que qualquer coisa exista (SAFRANSKI, RÜDGER). Heidegger, um mestre da Alemanha entre o bem e o mal. São Paulo: Geração Editorial, 2000. 
p.190.

${ }^{2}$ Entes - Palavra grega ou latina que hoje traduzimos por entes, não há tradução em português. As coisas que são agora. Os gregos usavam a palavra ou, assim como nós falamos, objetos. Ente em grego foi o conceito geral para objeto. Precisamos de uma palavra para falar de todas as coisas. Ser é sempre o ser de um ente. (HEIDEGGER, 1997).

${ }^{3} \mathrm{~A}$ expressão ôntico designa tudo que existe.

${ }^{4}$ A palavra Dasein significa literalmente "ser o aí" e por conseguinte se refere ao ser humano, aberto a si mesmo, ao mundo e aos demais seres humanos. A palavra Dasein significa literalmente existência, porém Heidegger a usa no sentido exclusivo de existência humana. (HEIDEGGER,1997 p.30).

5 Por campo entende-se todo o comportamento (incluindo ação, pensamento, desejo, busca, valorização, realização etc.) concebido como uma mudança de algum estado de um campo, numa determinada unidade de tempo. Por campo deve-se considerar o espaço de vida do indivíduo. Seu espaço de vida se constitui pela pessoa e do meio psicológico como ele existe para a pessoa. (LEWIN, 1965 p. XIII). 